\title{
Andrologie: een belangrijk aandachtsgebied voor de kwaliteit van leven van alle mannen!
}

\author{
H. M. K. Jetske van Breda - M. T. W. T. Tycho Lock
}

Geaccepteerd op: 17 januari 2022

(C) The Author(s) 2022

In september 2008, in het kader van de Europese Week van de Urologie, verscheen het allereerste themanummer, gewijd aan andrologie en functionele urologie, met als gastredacteur Eric Meuleman. In december 2018 waren Gert Dohle en Marije Dinkelman-Smit de gastredacteuren voor een themanummer over de andrologie alleen. En nu is er alweer een themanummer over andrologie voor $u$ samengesteld. Want mochten congressen en symposia de indruk wekken dat alleen de oncologische urologie in een stroomversnelling is gekomen, niets is minder waar. Dit geldt zeker ook voor de andrologie.

Ook al is er een toenemende verdeling gaande van 'aandachtsgebieden' over de diverse maatschappen, de raakvlakken daartussen blijven groot. Wij zijn er van overtuigd dat het voor de algemene uroloog van belang is, en ook interessant, om op de hoogte te blijven van álle veranderingen op urologisch vlak. Brede kennis zorgt voor adequate voorlichting en behandeling van de patiënt en, indien nodig, het kunnen doorsturen van de patiënt naar de juiste gespecialiseerde centra.

Een duidelijk voorbeeld van zo'n raakvlak is de behandeling van een 75+-man met een $\mathrm{N+-}$ of $\mathrm{M+-pros-}$ taatcarcinoom. Is er ruimte voor hormonale behandeling bij deze man, die al jarenlang een $\mathrm{BMI}>30$ heeft? We meten het zelden of nooit! Maar op grond van leeftijd en leefstijl zou deze man zomaar al een totaalen vrij testosterongehalte op castratieniveau kunnen hebben. En hebben we naast alle lastige oncologische details tijdens multidisciplinair overleg (MDO) voldoende oog voor klachten van hypogonadisme en metabool syndroom?

dr. H. M. K. J. van Breda · drs. M. T. W. T. T. Lock ( $ه)$ afdeling Urologie, Universitair Medisch Centrum Utrecht, Utrecht, Nederland

m.t.w.t.lock@umcutrecht.nl
'Meten is weten' gebruiken we graag binnen de urologie. Maar testosteron meten, kunnen we nog niet zo lang, het is pas minder dan 100 jaar geleden geïsoleerd. Rob Schipper neemt $\mathrm{u}$ mee langs ruim anderhalve eeuw wetenswaardigheden van dit hormoon.

Hypogonadale klachten kunnen soms met een 'niets kostend' tabletje behandeld worden. Anios Manou Huijben zette samen met Tycho Lock 10 jaar praktijkervaring op een rij.

Testosterontoediening is desastreus voor de patiënt met hypogonadisme en een actieve kinderwens, want zijn zaadproductie zal zienderogen afnemen. Medegastredacteur Jetske van Breda en Vincent de Kemp nemen u mee naar alternatieven.

Een op de zes vruchtbare mannen heeft een varicocele. Los van fertiliteitsproblemen krijgt elke uroloog hier vragen over: "Wordt het erger? Krijg ik later klachten? Kan die spatader barsten? Mijn zoontje heeft het ook." Marije Dinkelman-Smit geeft u evidence based informatie voor een helder gesprek met uw patiënt.

Geruime tijd moesten de patiënten implantatie van hun erectieprothese zelf betalen. Vanaf 1 januari 2016 is dit gelukkig in het basispakket opgenomen, mits voldaan wordt aan de NVU-criteria. Eveline Broers rapporteert namens de collega's van de zeven regio's de resultaten van de afgelopen vijf jaar. Een van deze centra is gespecialiseerd in het inbrengen van erectieprothesen bij transgender mannen. Garry Pigot, recent gepromoveerd op 'Gender Urology', rapporteert hierover.

Elk jaar wordt in Nederland bij ongeveer 450 personen jonger dan 18 jaar kanker vastgesteld. De nationale zorg voor deze groep patiënten wordt sinds 2018 verricht in het Prinses Máxima Centrum, gelegen naast het Wilhelmina Kinderziekenhuis te Utrecht. Een groot gedeelte van deze kinderen zullen behandelingen ondergaan die gonadotoxisch zijn. Joana B. Serrano en haar collega's gaan in op hoe kan 


\section{Editorial}

worden geanticipeerd op de kinderwens die deze mannelijke patiëntjes op volwassen leeftijd kunnen ontwikkelen. In het diermodel (muis, stier, apen) is het mogelijk gebleken door middel van stamceltransplantatie infertiele dieren gezonde zaadcellen te laten produceren die leidden tot gezond nageslacht. In het humane model kunnen stamcellen via een klein testisbiopt gecryopreserveerd worden. Mocht de eigenaar van deze stamcellen van kanker genezen, maar infertiel geworden zijn door de chemotherapie, en op volwassen leeftijd een vaderwens hebben, dan lijkt terugplaatsing in het rete testis van in het laboratorium geprepareerde stamcellen ook in het humane model mogelijk. Er zijn echter nog vele ethische en kankertechnische hobbels te nemen alvorens deze terugplaatsing op een veilige manier gerealiseerd kan worden.
Veel leesplezier gewenst en laat uw nieuwsgierigheid bevredigen.

Jetske van Breda en Tycho Lock, gastredacteurs

Open Access This article is distributed under the terms of the Creative Commons Attribution 4.0 International License (http://creativecommons.org/licenses/by/4.0/), which permits unrestricted use, distribution, and reproduction in any medium, provided you give appropriate credit to the original author(s) and the source, provide a link to the Creative Commons license, and indicate if changes were made.

dr. H.M.K. (Jetske) van Breda, uroloog

drs. M.T.W.T. (Tycho) Lock, uroloog 